\title{
Child Development Within The Framework Of Cultural-Historical Theory
}

\author{
E. Nihal AHIOGLU*
}

\begin{abstract}
The purpose of this paper is to present different aspects of Cultural-Historical Theory and examine their relevance to child development. It is discussed some important conceptual features of theory such as elemantary functions and higher psychological functions, tools and mediation, social interactions, zone of proximal development. In addition Vygotsky's a number of methodological points concerning the nature of psychological inquiry was examined. Finally to present theory's explanations about the relation between development and learning were determined the concepts of guided participation and scaffolding being within social interactions.
\end{abstract}

Key Words: Cultural-Historical Theory, The zone of proximal development, mediation in development and learning, scaffolding, guided participation.

* Dr.,Uludag University Faculty of Education, Bursa. e-mail: nihal2006@ gmail.com 


\section{SUMMARY}

Purpose and significance: Developmental psychology have not adequately focused on the social-cultural-historical aspects of development and even it (except some contextualists) has interested with the nature of particular tasks or domains of knowledge rather than the socially embedded nature of all types of knowledge. However Vygotsky's cultural-historical theory proposed that children's development is shaped largely by society and culture. The theory focused on the connections between people and the cultural context in which they act and interact in shared experiences.

Resources: According to Vygotsky, humans use tools that develop from a culture, such as speech and writing, to mediate their social environments. Initially children develop these tools to solve solely as social functions, ways to communicate needs. Vygotsky believed that the internalization of these tools led to higher thinking skills. According to him, the process of internalization occurs in the zone of proximal development. Vygotsky describes it as "the distance between the actual development level as determined by independent problem solving and the level of potential development as determined through problem solving under adult guidance or in collaboration with more capable peers" (Vygotsky, 1978). The zone of proximal development bridges that gap between what is known and what can be known.

Results: Vygotsky claimed that learning occurred in this zone. However, in the theory it was not defined how instructional interactions occur. This kind of interactions have determined differently according to qualitative nature of interactions after Vygotsky. Rogoff has suggested "guided participation" as a concept to examine the effects of all social environments (family, siblings, peers, school, teachers, and neighbors) and culture on child development. Wood has determined "scaffolding" as to examine adults' support or interventions in interactions. Both concepts rest on definitions of the zone of proximal development.

Conclusions: Vygotsky's theory is not known sufficiently in Turkish literature. Actually, its structure giving a clear value to interactions between adults and children in learning should be handled as a tool for improving learning environments such as home or school. Moreover it is believed that Vygotsky's ideas on relations between culture and child development and genetic analysis on child development is important for explaining and defining intra and inter cultural differences. 


\title{
Kültürel - Tarihsel Kuram Çerçevesinde Çocuk Gelişimi
}

\author{
E.Nihal AHİOĞLU*
}

ÖZ. Bu makalenin amacı, Kültürel-Tarihsel kuramın temel kavramlarını açıklamak ve kuramın çocuk gelişimine yönelik görüşlerini ortaya koymaktır. Çalışmada ilk olarak kuramın kültüre ve tarihe bakışı açıklanmıştır. Bunun yanında kuramın genelde psikoloji disiplini ve özelde de çocuk gelişimi ile ilgili kuramsal ve yöntembilimsel tartışmalarına yer verilmiştir. Kuramsal yönü ile ilgili olarak kuramın genel olarak insan gelişimini nasıl kavramsallaştırdığı üzerinde durulmuş; basit işlevler ve ileri psikolojik işlevler, aracılı araçlar ve işaretler, toplumsal etkileşim ve yakınsak gelişim alanı kavramları açıklanmıştır. Yöntembilimsel olarak ise, kuramda tartışılan yöntembilimsel özellikler üzerinde durulmuştur. Son olarak kuramın temel yapısı çerçevesinde tanımlanan öğretime dayalı farklı etkileşim biçimleri ve bunların temel özellikleri tartışılmıştır.

\section{Gİiș}

Çocukluk, evrensel bir olgu olarak her toplumda ve kültürde özel öneme sahip bir gelişim dönemidir. Buna bağlı olarak her toplumun, çocukluğa yönelik toplumsal, gelişimsel ya da kültürel yüklemelerinde farklılıklar bulunmaktadır. Fass'ın (2003) da belirttiği gibi, her kültür, çocukların neye benzediğine ilişkin görüşlerini ve kendi geleceğine dönük kültürel vizyonunu gerçekleştiren çocuklarla ilgili uygulamalarını göstermede kendine özgü yöntemler tasarlamaktadır. Bu doğrultuda Vygotsky çocuk gelişimini, "kültürel gelişim” olarak tanımlamakta ve kültürün belirleyici etkisini vurgulamaktadır (Wertsch, 1997).

\footnotetext{
*Dr., Uludağ Üniversitesi Eğitim Fakültesi, Bursa. e-mail: nihal2006@ gmail.com
} 
Vygotsky’e (1987a) göre, zamanına özgü psikoloji yaklaşımlarının en önemli eksikliği, bu kuramların davranışa yönelik açıklamalarının, daha çok belirli bir davranışa özgü doğal tepkileri içermesi ve davranışın nedensel dinamikleri konusunda yeterli açıklama yapamıyor olmalarıdır. Cole (1995), Wertsch, Del Rio ve Alverez'e (1995) göre, Vygotsky’nin -Marksist ideoloji temelinde- bilinç ve pratik etkinlik ilişkisi ile ilgili ilk varsayımı, pratik etkinliğin örgütlenme biçimindeki değişime bağlı olarak bilinç durumunun değiştiği ve bu değişimi tanımlamanın ancak tarihsel bir yaklaşım veya ayrıntılı "genetik analiz" yoluyla mümkün olacağı biçimindedir. Ona göre, genetik veya gelişimsel bir analiz yapılmaksızın, psikolojik bir olgunun sadece belli yönleri anlaşılabilir; ancak bu psikolojik olgu ile ilgili içsel ve nedensel dinamikler açıklanamaz. Bu doğrultuda Lee'e göre (1989), Vygotsky'nin kuramındaki en genel amaç, kuramsal ve yöntembilimsel olarak bilincin araştırılmasına uygun bir psikoloji yaklaşımı geliştirmektir.

Vygotsky'nin tarihsel yaklaşım olarak tanımladığı genetik analiz, en basit anlatımla "herhangi bir olguyu eylem boyunca inceleme" biçiminde tanımlanmaktadır (Scribner, 1989). Vygotsky'e (1978) göre;

“...davranışı tarihsel olarak ele alma, kuramsal çalışmaya ek ya da ona yardımcı bir yaklaşım değildir; aksine, kuramsal çalışmanın temelini oluşturmaktadır"'

Vygotsky, kuramında daha çok kişiye özgü tarih (ontogenesis) üzerinde durmaktadır (Scribner, 1989). Bilinçli davranışa ilişkin tam ve doğru bir değerlendirmenin ancak varolan gelişimsel işlevlerin tarihsel olarak açıklanması ile mümkün olacağını ileri sürmektedir. Böyle bir anlayış çerçevesinde Vygotsky, özellikle gelişimi etkileyen etmenlerden birinin ya da birkaçının engellenmesi veya bunlara müdahale edilmesi durumunda insanlardaki tüm pratik ve bilinçli etkinliklerin gelişiminin nasıl etkilendiği üzerinde durmaktadır. Böylelikle kuramda, psikolojik süreçlerin gelişiminin tek bir etmen veya açıklayıcı ilkeyle değil bunlar arasındaki karşılıklı etkileşimin analiz edilmesi yoluyla anlaşılabileceği iddiasında bulunulmuştur (Wertsch, 1997). Bu doğrultuda, Vygotsky çocuk gelişimini tek bir etmenle değil gelişimi etkileyen "çoklu güçler”le açıklamaktadır.

Vygotsky’nin tanımladığı bu çoklu güçler; evrimsel (filogenetik), tarihsel (historical) ve kişiye özgü (ontogenetik) gelişim alanları olarak tanımlanmaktadır (Vygotsky ve Luria, 1994). Ona göre kültürel hale gelen insan davranış gelişimi, bu üç alanın ortak sonucudur. Evrimsel gelişim özellikleri, insanın diğer türlerle paylaştığı tüm ortak biyolojik gelişim özelliklerini içermektedir (Wertsch, 1997). Vygotsky (1985) bu gelişim özellikleri ile ilgili olarak özellikle Köhler, Pavlov ve Bühler'in maymunlarla yaptığı çalışmalara değinmekte ve ilkel insan ile diğer türlerin davranışsal özelliklerindeki benzerlik ve farklılıklar üzerinde durmaktadır. $\mathrm{Bu}$ araştırmacılar, dil öncesi dönemdeki çocukların herhangi bir hedefe ulaşmadaki araç kullanma biçimlerinin, maymunlarınkine benzediğini belirtmekte ve bunu 
maymun ve insanın düşünme biçimlerindeki önemli bir benzerlik olarak yorumlamaktadırlar. Ancak Vygotsky’e (1978) göre Köhler, araç kullanımı ile ilgili bu benzerliğin konuşma becerisinin kazanılmış olup olmaması ile bağlantısını göstermekle birlikte bunun nasıl olduğunu yani kazanım sürecini açıklamamaktadır. $\mathrm{Bu}$ bağlamda Vygotsky, davranışı açıklamaya yönelik "nasıl” sorusunun, genel tarihe yönelik, süreç temelli bir inceleme ve açıklamayı gerektirdiğini ileri sürmektedir. Vygotsky'e göre insanın genel tarihi içinde kazandığı beceriler, tek başına biyolojik evrimin bir sonucu değildir, yani sadece biyolojik gelişme ya da evrimin yasaları ile açıklanamaz. Kuramda, genel tarih, insanoğlunun evrimi ile ilgili zaman dizinine dayandırılmaktadır. Bir davranışa özgü genel tarih özellikleri, o davranışın gelişiminin biyolojik ya da doğal yönleri yanında kültürel yönleri ile bağlantılı maddi (işaretler ve araçlar) özellikleri de içermektedir. Çocuk gelişimi ile bağlantılı olarak düşünüldüğünde, bu genel tarihsel bakış, özellikle konuşma, planlama ve kendini kontrol etme gibi karmaşık becerilerin kazanılmasını açıklayabilmenin ön koşulu olarak değerlendirilmektedir. Bununla birlikte, bu karmaşık becerilerin bütün olarak tanımlanması, genel tarihsel özellikler yanında, ontogenetik özelliklerin incelenmesini de gerektirmektedir.

Ontogenesis ya da "çocuğa özgü tarih", genel tarihle benzer özelliklere sahiptir. Çocuğa özgü tarih, genel tarihten farklı olarak davranışın insana özgü, biricik yönlerini içermektedir. Biyolojik yasalar -tıpkı genel tarihte olduğu gibiçocuğun kültürel gelişimini açıklamada tek başına yeterli değildir. Bu nedenle, gelişimin biyolojik ve kültürel yönlerini ayırmak gerekmektedir. Biyolojik süreçler, çocuğun organik büyüme ve olgunlaşma süreçleri ile ilgiliyken, toplumsal ve kültürel süreçler, kültürel davranış biçimlerinde uzmanlaşma ve yeni akılyürütme yöntemlerini edinme gibi psikolojik işlevlerdeki kültüre bağlı gelişimi yansitmaktadır (Vygotsky, 1994b).

Gelişimin biyolojik ve kültürel yönleri, niteliksel olarak birbirlerinden farklı olmakla birlikte, temelde birlikte işleyen süreçlerdir. Buna göre çocuk fiziksel olarak büyüdükçe ve kendi davranışları üzerindeki kontrolü arttıkça, aynı zamanda konuşma gibi işaret ve araçları kullanma ile ilgili becerileri de artmaktadır (Vygotsky, 1978). Vygotsky, bu noktada özellikle çocuk gelişimindeki yaşa bağlı niteliksel değişimler üzerinde durmaktadır. Ona göre yaş, geçici bir özellikten çok psikolojik bir kategoriyi ya da gelişim dönemini ifade etmektedir. Böylelikle yaşın, daha çok kültürel/toplumsal yönleri vurgulanmaktadır (Van Der Veer, 1986; Chaiklin, 2003). Kurama göre yaş kavramının, hem tarihsel hem de araçsal yönleri vardır. Yaşın tarihselliği, bu dönemlere özgü işlevlerin çocuğun deneyimleri ya da eylemleri sonucunda oluşması ile ilgilidir. Yaş dönemlerinin araçsallığı ise, işlevlerin diğer insanlarla etkileşimler ve bu etkileşimler sırasında yerine getirilen görevlerin bir sonucu olarak gelişiyor olmasını içerir. Her bir yaş dönemi, hangi psikolojik işlevlerin geliştiğine bağlı olarak o yaş dönemine özgü yeni ve merkezi bir "yeni oluşum"u içermektedir. Bu yeni oluşum, çocuğun var olan özellikleri ile onun ihtiyaçları, arzuları, yaşadığı çevrenin istekleri ve sağlayabilecekleri arasındaki 
çatışmalar yoluyla oluşturulmaktadır. Sabit büyüme dönemlerini, ani dönüşümler, duraklama ve hatta gerileme dönemleri izlemektedir (Vygotsky, 1978).

Vygotsky pratik etkinliğin gelişiminin, çocukla çevresi arasındaki krizlerin, çatışmaların ve köklü değişikliklerin eşlik ettiği "diyalektik bir süreç" içerisinde söz konusu olduğunu belirtmektedir. Bu diyalektik süreçte toplumsal etkileşimler özellikle önemli görülmektedir (Lee, 1989). Çocuk her bir yaş evresine özgü çatışmanın üstesinden gelmek için, yeni işlevlerin oluşmasına ya da varolanların gelişmesine yol açan farklı somut görevlere ve o duruma özgü toplumsal etkileşimlere yönelir. Böylelikle, belirli bir yaş dönemine özgü yeni işlev, çocuğun henüz uzmanlaşmamış olduğu bir psikolojik işlev ile ilgili toplumsal etkileşimlerinin sonucu olarak ortaya çıkar (Van Der Veer, 1986; Fernyhough, 1996; Wells, 1999). $\mathrm{Bu}$ diyalektik süreçte, hem eylemin kendisine hem de değişime özgü psikolojik süreçler üzerinde durulmaktadır.

Vygotsky'e göre bilince ve pratik etkinliğe ilişkin sözü edilen yeni işlev biçimleri, farklı örgütlenme ve gelişim ilkelerini gerektirmektedir. Özellikle dil gibi diğerleri ile iletişimi mümkün kılan bir psikolojik aracın çocuk tarafindan kullanılmaya başlanması, insanı diğer türlerden ayıran önemli bilişsel ve gelişimsel farklılıklara neden olmaktadır. Bu tür bir farklılık temelde insanın sahip olduğu ileri psikolojik işlevler ile yakından ilgilidir (Van Der Veer, 1986, Lee, 1989).

\section{Basit ve İleri Psikolojik İşlevler}

Vygotsky (1978) psikolojik gelişmeyi, davranışın doğrudan, doğuştan ve doğal biçimlerinden, kültürel gelişim sürecinde oluşan dolaylı ya da aracılı, yapay psikolojik işlevlere geçiş olarak tanımlamaktadır. $\mathrm{Bu}$ doğrultuda, davranışın doğuştan, doğrudan çevreden gelen uyaranlara bağlı olarak oluşan doğal biçimleri, "basit işlevler" (elementary functions) olarak tanımlanmaktadır. Buna karşılık davranışın kendi kendine üretilen (self-generated), aktarılan, yani doğrudan nedenleri olan yapay biçimleri ise "ileri psikolojik işlevler" (higher psychological functions) olarak tanımlanmaktadır. Basit işlevlerin, tüm türlere özgü biyolojik temelleri vardır. $\mathrm{Bu}$ işlevler daha çok çevreden gelen uyaranlara verilen ani tepkilerle tanımlanmaktadır. Algı, bellek, dikkat gibi bilişsel işlevlerin ilkel, doğal ya da ilkel tepkiye dayalı, kendiliğinden olan ve değişken doğalı ilk biçimleri basit işlevlerin kapsamına girmektedir. Böylelikle bu işlev türü, en ilkel bilişsel özellikleri içermektedir (Ratner, 1998). Örneğin bir bebeğin yatağının üstünden sarkan bir oyuncağa refleksif olarak dikkat etmesi; basit, istemsiz, biyolojik olarak programlanmış evrimsel temelli bir uyum sağlamadan başka bir şey değildir.

İleri psikolojik işlevleri basit işlevlerden ayıran en önemli farklılık, bu işlevlerin çocuk tarafindan, onun diğerleri ile etkileşimleri sonucunda oluşturuluyor olması ve daha da önemlisi, basit psikolojik işlevlerin dönüşümüne dayanmasıdır. $\mathrm{Bu}$ dönüşümün kültürel bir yönü vardır. Buradaki kültürel özellik, ileri psikolojik işlevlerin toplumsal deneyimler yoluyla uyarılıyor ve bunlara bağlı olarak düzenleniyor olmalarından kaynaklanır. Buna göre çocuk, toplumsal deneyimleri ya 
da etkileşimleri sonucunda elde ettiği bir uyaranı, aracılı ya da dolaylı araçlar yardımıyla yeniden düzenlemekte, biçimlendirmekte ve içselleştirmektedir. $\mathrm{Bu}$ doğrultuda kültürel gelişimin en genel yasası şöyle özetlenmektedir:

"bütün ileri psikolojik işlevler iki defa ya da iki düzlemde görünür. İlk olarak toplumsal düzlemde ve sonra da psikolojik düzlemde. Illk olarak kişilerarası (interpersonal) bir özellik olarak kişilerarasında ve sonra da kişiye özgü (intrapersonal) bir özellik olarak çocuğun kendi içinde görünür" (Vygotsky, $1978: 57$ )

Davranışın toplumsal olarak düzenlenmesi ile düşünmenin bireysel düzenlemesi arasındaki bu bağlantı, toplumsal etkileşimlerin biçimini ve düzeyini belirleyen en önemli ilkedir. Vygotsky çocuğun toplumsal etkileşimleri yoluyla her bir gelişim dönemi için ayrı, soyut bir psikolojik yapı oluşturduğunu ileri sürmektedir. Bu psikolojik yapı temelde algı, seçici dikkat, konuşma, düşünme gibi psikolojik işlevler arasındaki sarmal ilişkiler ağını betimlemektedir. Psikolojik bir bakış açısıyla bu "sarmal ilişkiler ağı", araçsal etkileşimler yoluyla kazanılan gelişmiş ve daha sonraki ilişkiler nedeniyle de gelişmeye devam eden ileri psikolojik işlevler arasındaki bütünleşmiş bir ilişki yapısı olarak tanımlanabilir.

Vygotsky (1994b) ileri psikolojik işlevlerin gelişim sürecinde toplumsal etkileşimler yanında biyolojik temellerin ve organik yapının da önemli olduğunu iddia etmektedir. Ancak ileri psikolojik işlevlerin, daha ilkel ve biyolojik kökenleri olan basit işlevlerin devamı ya da onun sonucunda oluştuğunu söylemek doğru olmayacaktır. Başka bir deyişle ileri psikolojik işlevler, temel psikolojik süreçleri tanımlayan türe özgü gelişimin (filogenesis) bir özeti değildir. Aksine, ileri psikolojik işlevler; toplumsal etkileşimlerin belirlediği özerk, kendine özgü özellikleri olan ayrı yapılardır (Wertsch, 1997). Bu noktada belirtilmesi gereken önemli bir nokta, Vygotsky'nin, davranışın ileri biçimleri ile ilgili evre benzeri gelişimsel bir dizge ileri sürmemiş olmasıdır. Scribner'a (1989) göre bunun nedeni, onun ileri sistemleri, düşünmenin genel modelleri ya da zekanın genel yapıları olarak tanımlamıyor olmasıdır. Kuramda her bir ileri psikolojik işlevin (örneğin sayı sayma, bellek, yazı yazma gibi) eş zamanlı bir tarihsel gelişim göstermediği ileri sürülmektedir. Hepsi de ilkel düzeyden ileri düzeye doğru gelişmektedir, ancak gelişimlerinin yönü ve hızı farklıdır. Belli bir toplumda her psikolojik işlevin, kültüre özgü araçsal anlamının farklı olması beraberinde tüm işlevlerin aynı düzeyde ve hızda gelişmemesi sonucunu ortaya çıkarmaktadır.

\section{Aracilı Araçlar}

Vygotsky kuramında, toplumsal etkileşimlerin en önemli özelliğinin, eyleme aracılık eden araçları içermesi olduğunu belirtmektedir. Onun kuramında, insanlık tarafindan yapay olarak kendi tarihi içinde geliştirilen tüm araçlar, kültürün elemanları olarak değerlendirilmektedir (Davydov ve Radzikhovskii, 1989). Vygotsky bu araçları, teknik ve sembolik (işaret) araçlar olarak iki gruba ayırmaktadır. Teknik araçlar, 8 aylık bir bebeğin oyuncağına ulaşmak için yatak 
örtüsünü kullanması ya da bir maymunun muza ulaşmak için bir sopa kullanması örneklerindeki araç kullanımı ile açıklanabilir. Vygotsky (Kozulin ve Presseisen, 1995) bu araçların bireysel araçlar olarak var olmadığını, onların kolektif kullanımın, kişilerarası iletişim ve sembolik temsilin ön koşulu olduğunu belirtmektedir. İkinci gruptaki aracılı eylemlerin bu sembolik yönü, sembolik ya da psikolojik araçlar olarak kavramsallaştırılmaktadır.

Vygotsky'nin kuramında sembolik araçlar ya da işaretler, bilişsel gelişimin en önemli temel itici gücü olarak değerlendirilmektedir. Sembolik araçlar, bir kültürün tarihi içinde o anı ve bağlamı paylaşan insanlar tarafindan oluşturulmaktadır (Wells, 2006). Vygotsky en eski psikolojik araçlar olarak -ki bunlara psikolojik fosiller demektedir- sayışma, bağcık bağlama ve parmak saymayı belirtmektedir (Vygotsky, 1978). Bunlar dışında en önemli sembolik araç, dil ya da konuşma becerisi olarak tanımlanmaktadır. Ayrıca değiş̧ik sayma sistemleri, bellek teknikleri (örneğin farklı bir dile ait kelimeleri hatırlayabilmek için kelime köklerine ya da bunların anadille benzerliklerine dikkat etme), matematiksel semboller, sanatsal işler, şemalar, grafikler, haritalar ve mekanik çizimler, tüm geleneksel işaretler ve daha pek çok kültüre özgü sembol de bu grup içerisinde yer almaktadır. Kuramda sembolik araç ya da işaretlerin, hem bilginin karşılıklı yapılandırılmasını sağladıkları, hem de gelecekteki problem çözme eylemlerinde yardımcı olan içselleştirilmiş anlamlar oldukları iddia edilmektedir (Kozulin, 1999; Wertsch, 1997). Bu nedenle teknik araçlardan farklı olarak tanılayıcı özelliğe sahip "psikolojik araçlar" biçiminde tanımlanmalarının doğru olacağı belirtilmektedir (Davydov ve Radzikhovskii, 1989).

Bir sembolik (psikolojik) araç veya işaret (sign), insanın belli bir alandaki deneyimlerinin temelini oluşturmaktadır. Çocuk işaretleri ya da sembolik araçları kullanarak, biyolojik gelişiminden farklı özel bir davranış yapısı ve kültürel temelli yeni psikolojik işlev biçimleri oluşturmaktadır. Vygotsky bu yeni psikolojik işlev biçimlerinin oluşturulması sürecinde çocuğun aktif olduğunu ve bu işlemin çevre temelinde değil, birey temelinde gerçekleştiğini belirtmektedir (Vygotsky, 1978).

Vygotsky'e göre (1978) dil bir psikolojik işlev biçimi ve işaret olarak, hem ileri işlevlerin içselleştirilmesi hem de basit işlevlerin ileri işlevlere dönüşümü sürecinde önemli bir etmendir. İleri psikolojik işlevlerin gelişiminin, çevreyle ilişkiler temelinde gerçekleştiği düşünüldüğünde, bu ilişkiyi sağlayan temel aracı (mediation), çocuğun yaşadığı toplumsal çevredeki diğer insanlar tarafindan paylaşılan dil sistemidir. Vygotsky (1994b) dilin bilişsel gelişime yönelik bu aracılı işlevi nedeniyle en önemli işaret ya da sembolik araç olduğunu belirtmektedir.

Vygotsky'e göre çocuklar, varolan psikolojik gelişim özelliklerinin yeterli olmadığı bir problem durumu ile karşılaştıklarında bir dizi karmaşık tepki gösterirler. Bu tepkilerden ilki, insanın diğer türlerle de paylaştığı bir etkinlik biçimi olarak nesneye dönük doğrudan bir eylemde bulunmadır. Problem bu tür etkinliklerle çözülemediğinde çocuk bu durumda, bir yandan çözüme yönelik 
denemelerine devam ederken bir yandan da başka bir insandan sözel olarak yardım isteğinde bulunur. Vygotsky'e göre (Vygotsky ve Luria, 1994) bu tür bir yardım isteği, gerçekte çocuğun o problemin çözümü ile ilgili bir planı olduğunu ancak çözüme ulaşmasını sağlayacak bilişsel işlem basamaklarının eksikliğini göstermektedir. Bununla birlikte konuşmaya dayalı bu tür etkileşimler, çocuğun belirli bir problem durumuna ilişkin bilişsel nitelikli planlama becerisinin gelişimi açısından da önemlidir. Ancak çocuklar, toplumsal olarak yeterli bir destek alamadıklarında ya da problemi bu yardıma rağmen çözemediklerinde (ya da kimi zaman problemi çözüm sürecinde), problem durumunun odağındaki nesnenin kendisine yönelik doğrudan ve kendilerini merkeze alan bir sözel başvuruda bulunmaktadırlar (Vygotsky, 1994c).

Vygotsky (1994b), dışsal olandan içsel olana geçişin bir göstergesi olan bu son evrenin, düşünme ve konuşmanın gelişimindeki en önemli evre olduğunu belirtmektedir. $\mathrm{Bu}$ evredeki sözel davranış, Piaget'nin "benmerkezci konuşma" kavramına benzemekle birlikte Vygotsky bu duruma Piaget'den çok farklı bir bakış sunmuştur. Öncelikle Piaget benmerkezci konuşmada çocuğun, diğer insanlardan çok kendisi ve kendi eylemine dönük olduğunu ve diğerinin eyleme dönük sözel tepkilerini dikkate almadığını belirtmektedir (Piaget ve Inhelder, 1969). Ona göre çocuğun eylem anında yaptığı bu tür konuşmalar aslında kendi kendine konuşmaktan farklı değildir. Piaget bu durumun ayrıca düşüncenin gelişimi açısından hiçbir işlevi olmadığını ve okul yıllarında yerini toplumsallaşmış konuşmaya bıraktı̆̆ını da iddia etmektedir. Bununla birlikte Vygotsky (1985: 36) Piaget'nin bu iddiasına karşı çıkarak,

"benmerkezci konuşma, ...kisa sürede, bir probleme çözüm arama ve çözümü tasarlama sürecinde, gerçek anlamda, düşüncenin bir aracı haline gelir" demektedir.

Vygotsky, benmerkezci konuşma ve eylem arasındaki bu ilişkinin, gelişim sürecinde çok karmaşık bir değişim gösterdiğini belirtmektedir. Gelişimin erken dönemlerinde benmerkezci konuşma, eylemin sonucunu ya da eylemdeki bir dönüm noktasını simgelerken, daha sonraki dönemlerde etkinliğin ortalarına ve sonra da etkinliğin sonuna kaymaktadır. $\mathrm{Bu}$ son durumda, konuşma artık yönlendirici ve tasarlayıcı bir işlev kazanarak çocuğun yaptıklarını "amaçlı davranış" düzeyine yükseltmektedir. Vygotsky (1985: 37) bu durumu, çocuğun yaptı̆̆ı resimlere isim vermekte izlediği gelişimle örneklendirmektedir:

"Küçük bir çocuk önce resmi çizer, çizdiğinin ne olduğuna sonra karar verir; biraz daha büyüyünce, resim yaparken adın koyar; sonunda ise, ne çizeceğine önceden karar vermeye başlar".

Vygotsky'nin (1978) Piaget'nin benmerkezci konuşma ile ilgili görüşlerine yönelik ikinci karşıt iddiası ise bu gelişim evresinin yaşandığı zamanla ilgilidir. Piaget (Piaget ve Inhelder, 1969) benmerkezci konuşmanın konuşma gelişiminin ilk evresi olduğunu ve toplumsallaşmış konuşmanın bundan sonra oluştuğunu 
belirtmektedir. Vygotsky (1987b), bunun aksine benmerkezci konuşmanın, dil gelişiminin ilk evresi değil, ikinci ara evresi olabileceğini iddia etmektedir. Ona göre gelişimin ilk aşamalarında, çocuğun dil kullanımı, daha çok iletişimsel bir anlam taşımaktadır. Yani çocuk, gelişimin ilk aşamalarında toplumsal etkileşime dönüktür. Ancak çocuk herhangi bir problem durumuyla karşılaştı̆ıında ve bu problemi sahip olduğu dişsal (toplumsal) araçlarla çözemediği durumlarda psikolojik bir araç olan benmerkezci konuşmaya başvurmaktadır. Benmerkezci konuşma, tekrarlı deneyimler ve etkileşimler sonucunda içsel konuşmanın (inner speech) gelişmesini sağlamaktadır. İçsel konuşma evresi, içerdiği psikolojik dönüştürmeler nedeniyle düşüncenin gelişimi açısından önemli bir dönüm noktası olarak değerlendirilmektedir (Wood, 1998). Bu dönüşüm, dışsal (interpersonal) olanın içsel (intrapersonal) olana dönüşümünü içermektedir.

İçsel konuşmada çocuklar öncelikle, daha önce bir başka kişiyle ilişkilerinde kullandıkları ve davranışlarına yön veren bir davranış yöntemi geliştirirler, yani kendi eylemlerini toplumsal bir davranış biçimine göre düzenlerler. Daha sonra ise, kendi kendilerine geliştirdikleri bu işaret (eyleme özgü davranış biçimi ve aynı zamanda bir psikolojik araç) yoluyla toplumsal olanı içe alır ve kendi davranışlarına uyarlarlar. Bir anlamda toplumsal ve içsel konuşmanın bir arada yer alması, çocukların eyleme dönük plan yapmalarını sağlamaktadır. Dilin aracı niteliği sayesinde kolaylaşan eylemler, son olarak bütün ileri psikolojik işlevlerden sorumlu olan pratik zekanın gelişmesini sağlamaktadır. Psikolojik araçların, toplumsal olandan içsel olana doğru gelişimini içeren bu dönüşümü (içselleştirme), ileri psikolojik işlevlerin gelişiminde önemli olması yanında çocuğun daha sonraki zeka ve üreticiliğine temel sağlaması açısından da önemlidir (Vygotsky, 1978; Vygotsky ve Luria, 1994).

Sonuç olarak, aracılı araçlar yoluyla gerçekleşen içselleştirme sürecinde özetle üç tür bilişsel temelli dönüştürme yapılmaktadır:

1- Başlangıçta dışsal bir eyleme işaret eden bir psikolojik işlem, çocuk tarafindan yeniden yapılandırılmakta ve içsel olarak varolmaktadır.

2- Kişilerarası bir süreç, kişisel olana dönüştürülmektedir. Buna göre ileri psikolojik işlemlerin tamamı, insanlar arasındaki gerçek ilişkilerle başlamaktadır.

3- Kişilerarası bir sürecin kişisel bir sürece dönüşmesi, bir dizi uzun gelişimsel değişmeyi içermektedir. Dönüştürülen psikolojik süreç, varolmaya ve betimsel olarak içe doğru dönmeden önce uzun bir zaman dışsal bir eylem biçimi olarak değişmeye devam etmektedir. Burada eylemin tekrarlı doğası önemli bir etmendir. Bununla birlikte bütün dışsal işaretler, içe dönüştürülmemektedir. Bu daha çok kültüre özgü özelliklerle bağlantılıdır. Böylelikle kimi psikolojik süreçler, içselleştirilmeden dışsal olarak varolmaya devam ederken kimileri de içsel işlem olana kadar yavaş ve oldukça kararı bir gelişim göstermektedirler. Bu süreçteki en önemli nokta, içsel olana dönüşümün bu süreci yöneten kültürel / toplumsal kurallardaki değişimlerle de bağlantılı olmasıdır (Vygotsky, 1978). 


\section{Yakınsak Gelişim Alanı}

Vygotsky (Wertsch, 1997) tanılayıcı bir ilke olarak yakınsak gelişim alanını (the zone of proximal development), bilişsel gelişimin kendi sürecini tanımlayan içsel / nedensel dinamikleri ve genetik bağlantıları belirlemede ve açıklamada kullanılabilecek bir mekanizma olarak belirtmektedir. Leont'ev'in (akt. Wertsch, 1997) ifadesi ile yakınsak gelişim alanı, çocuğun henüz ulaşmadığı bir gelişim düzeyine "nasıl ulaşabileceğini" göstermektedir. Bununla birlikte yakınsak gelişim alanı, Vygotsky’nin çocuğun gelişimini açıklamaya yönelik kuramının temel veya ana kavramlarından biri değildir. Bu kavram daha çok, çocuğun gelişimindeki özel bir anı ve zamanı vurgulamak için kullanılmaktadır (Cole, 1989; Wertsch, 1997). Kuramda yakınsak gelişim alanı,

“...çocuğun bă̆ımsız problem çözme becerisi olarak tanımlanan varolan gelişim düzeyi ile problemi yetişkin rehberliği ya da daha yetkin akranlarla işbirliği yaparak çözebilmesi anlamına gelen potansiyel gelişimin ileri düzeyi arasındaki uzaklık" olarak tanımlanmaktadır (Vygotsky, 1978 : 86).

Kavramın içeriğindeki "yakınsak" tanımlaması; sağlanan yardımın öğrenen kişiyi, onun tamamlanan ve varolan becerileri üzerine kurulan şu anki yeteneğinin sadece biraz ilerisine götürdüğünü göstermektedir (Cole, 1989 ). Buna göre çevre, çocuğun sadece varolan becerileri ya da olgunlaşan özellikleri çerçevesinde gelişmeyi sağlar. Yakınsak gelişim alanı bu çerçevede, varolan gerçek özellikler çerçevesinde gelişebilecek potansiyel gelişim özelliklerini belirlemektedir.

Vygotsky'nin yakınsak gelişim alanına ilişkin tanımı, üç temel açıklayıcı varsayıma dayanmaktadır (Chaiklin, 2003). Birinci varsayım olan "genellik" varsayımı, bir kişinin tek başına belli sayıda görevi başarabilirken, işbirliği ile daha çok sayıda görevi başarabileceği fikrine dayanmaktadır. Ancak burada vurgulanan bireyin işbirliği ile yapabildiği görevlerin oranı değil, genel olarak gelișiminin düzeyidir. Buna göre, belirli bir konu ile ilgili görevler (örneğin bir resim tamamlama görevi) gelişim düzeyini tanımlamada sadece bir araçtır. Böylelikle, yakınsak gelişim alanı, belirli bir göreve özgü becerilerin gelişmesinden (öğrenme) çok, gelişim sürecinin kendisi ile ilgilidir. Bu durum yakınsak gelişim alanının işlevselliğinin de önemli kanıtlarından biridir. İkinci varsayım, "yardım etme" (assistance) varsayımıdır. Bu varsayım, yetişkinin, öğretmenin ya da daha yetenekli akranın çocukla nasıl etkileşime girmesi gerektiği ile ilgilidir ve kimi zaman bütün olarak kavramı tanımlayıcı bir özellik olarak değerlendirilmektedir (Chaiklin, 2003). Vygotsky (1985) çocuğun işbirliği, yönlendirme ve yardım yoluyla, bağımsız bir biçimde yapabildiklerinden daha fazla ve daha zor görevleri başarabileceğini belirtmektedir. Ancak burada vurgulanan çocuğa yardım eden kişinin özellikleri değil çocuğun öğrenme ve gelişiminde, bu yardımın ya da işbirliğinin anlamıdır. Son olarak "potansiyellik" varsayımı, öğrenen kişinin özelliklerini ya da varolan gelişim potansiyelini ya da öğrenmeye hazır olma durumunu vurgulamaktadır. 
Kuramda, öğretim amaçlı etkinliklerin, yakınsak gelişim alanının ortaya çıkmasını sağladığı vurgulanmakla birlikte, yetişkinle işbirliğine dayalı öğretim amaçlı etkileşimlerin kendi başına, rastlantısal bir biçimde, çocuğun potansiyel gelişim düzeyini geliştireceği fikrine karşı çıkılmaktadır. Vygotsky aksine, çocuğun ancak kendi gelişim ve bilişsel potansiyel düzeyinin belirlediği kesin sınırlar içerisinde ilerleme gösterebileceğini belirtmektedir. Vygotsky'e göre (1978 : 80) "gelişim, öğrenme için bir ön gerekliliktir ve eğer çocuğun bilişsel işlevleri belirli bir konuyla ilgili yeteneği çerçevesinde olgunlaşmamışsa öğretim, bu durumda yarar sağlamayacaktır." Öğretim, kişilerarası psikolojik işlevlerin kişiye özgü psikolojik işlevlere dönüşmesini sağlar ve bu da gelişimi mümkün kılar. Ancak öğretimin, belirtildiği gibi çocuğun gelişen ya da gelişmekte olan özellikleri çerçevesinde olması gerekmektedir.

Vygotsky (1978) yakınsak gelişim alanının olgunlaşan işlevleri temel aldığı için, gelecekteki bilişsel gelişimi yordamada, sadece performans ölçümüne dayalı bir ölçmeye göre daha iyi bir yordayıcı olduğunu ileri sürmektedir. Vygotsky (akt. Wertsch, 1997 : 68) yakınsak gelişim alanının bu özelliğini şu örnekle açıklamaktadır:

"İki çocukla çalıștı̆ğnızı ve bunların zeka yaşlarının 7 olduğunu düşünün. Bu, her ikisinin de verilen görevleri 7 yaşındakilerin özelliklerine uygun bir biçimde çözecekleri anlamina gelir. Bununla birlikte, bu çocukları daha ileri düzeydeki testleri almaya zorladığımızda ikisi arasında temel bir farklılık olduğu ortaya çıkar. Yol açıcı sorular, örnekler ve model olmanın yardımıyla, bu çocuklardan biri, kendi (gerçek) gelişim düzeyinin 2 yll üstündeki test maddelerini çözer. Diğeri ise (gerçek) gelişim düzeyinin ancak 6 ay ilerisindeki test maddelerini çözer. O halde bu iki çocuğun bilişsel gelişim düzeyleri aynı mıdır? Gerçek gelişsim düzeyleri açısından baktığımızda, gelişim düzeyleri eşittir, ancak o anki potansiyel gelişim düzeyleri açısından baktığımızda kesinlikle birbirlerinden farklıdır.....böylelikle bu yöntem (yakınsak gelişim alani) yardımiyla biz, gelişmekte ya da olgunlaşmakta olan süreçleri de değerlendirebiliriz."

Böylelikle bir yordayıcı olarak değerlendirildiğinde yakınsak gelişim alanı, çocuğun psikolojik gelişiminin analizinde iki farklı amaç için kullanılmaktadır (Brown ve Ferrara, 1989; Smagorinsky, 1995). Bunlardan ilki yakınsak gelişim alanının, bir gelişim evresinden diğerine geçiş için gerekli olan ve olgunlaşmaya devam eden psikolojik işlev (ve onlarla ilgili toplumsal etkileşim) türlerini tanımlamada yani bir evreden diğerine geçiş sürecinde söz konusu olan değişimin kaynağının belirlenmesinde kullanılmasını içermektedir. Chaiklin (2003) yakınsak gelişim alanının bu özelliğini tanımlamak için "yakınsak gelişimin nesnel alanı" (objective zone of proximal development) tanımlamasını yapmaktadır. Her bir yaş dönemi, bazı psikolojik işlevlerin diğerlerine göre daha baskın olduğu bir psikolojik yapı ile tanımlanmaktadır. Buna göre her bir yaş evresinde, o evreye özgü yeni oluşumla bağlantılı olarak olgunlaşan bir grup psikolojik işlev vardır. Bu psikolojik 
işlevler, yeni bir bilişsel yapının oluşturulması sürecinde varolan işlevlerin yeniden düzenlenmesini sağlamaktadır. Yeni psikolojik yapı, aynı zamanda bir sonraki yaş dönemine geçişin de temelini oluşturmaktadır. Bu bağlamda çocuğun şu anki yaşı (yani o yaşa özgü olduğuna inanılan psikolojik işlevler) olgunlaşan işlevler; sonraki yaş evresine özgü özellikler de yakınsak gelişimin nesnel alanı olarak tanımlanmaktadır (Chaiklin, 2003). Bu alan, çocuğun bireysel özelliklerini değil, onun bir sonraki döneme geçmesi için ondan önceki yaş döneminde oluşturması gereken psikolojik işlevleri yansıttığı için nesnel bir nitelik kazanmaktadır. Böylelikle temelde vurgulanan şey, yukarda da belirtildiği gibi çocuğun bir yaş döneminden diğerine geçiş sürecinde gösterdiği değişimdir. Değişimin odağında da örneğin kavramlarla düşünme gibi bir psikolojik işlev vardır. Yakınsak gelişim alanının diğer işlevi ise, psikolojik gelişim için gerekli bu işlevlerin içselleştirilmesi ile bağlantılı olarak çocuğun varolan gelişimsel durumunu betimlemeyi ya da değerlendirmeyi mümkün kılmasıdır (Brown ve Ferrara, 1989; Smagorinsky, 1995). Chaiklin (2003) bu özelliği, "yakınsak gelişimin öznel alanı" (subjective zone of proximal development) olarak kavramsallaştırmaktadır. Yakınsak gelişimin öznel alanı, çocuğun şu anki gelişimsel durumunun, sonraki yapısal değişikliklerin ne kadarını açıklayacağına ilişkin bir tür değerlendirmeyi içermektedir. Farklı yaşlardaki çocuklar için öznel alan, benzer özellikler göstermekle birlikte çocukların bu öznel alanla bağlantılı nesnel pozisyonları farklıdır. Vygotsky’e göre (1978; 1994a), olgunlaşan işlevler belirli bir yaş döneminin içsel yapısındaki değişimlerin temelini oluşturduğu gibi onu diğer yaş dönemlerinden ayıran özelliklere de sahiptir. Yani psikolojik işlevlerin olgunlaşması, varolan yaş dönemine özgü yapılarda bir takım değişimlere neden olmaktadır. Ancak bu değişim sürecinde (içselleştirmeye yönelik dönüştürmeler) çocuğun sahip olduğu ancak olgunlaşmaya devam eden işlevler, o yaş dönemine özgü bağımsız eylemler için yeterli olmayacaktır. Bu nedenle bu işlevleri, gelişimin kapsamını tahmin etmeyi mümkün kılan ipuçlarını içeren, dinamik ve etkileşime dayalı yöntemlerle tanımlamak gerekmektedir. Bu doğrultuda yakınsak gelişimin öznel alanı; çocuğun olgunlaşan işlevlerinin, bir sonraki gelişim dönemini tanımlayan yapısal değişikliklerle ilişkisini göstermekte kullanılmaktadır. $\mathrm{Bu}$ alanın öznel olarak nitelenmesinin nedeni, bir kişinin psikolojik gelişimini, nesnel ve tarihsel olarak biçimlenmiş bir sonraki gelişim dönemi ile bağlantılı olarak (yani nesnel alanla) açıklama çabasından kaynaklanmaktadır. Yakınsak gelişimin öznel alanı ile ilgili en önemli kavram "taklit" olarak değerlendirilmektedir (Chaiklin, 2003). Vygotsky (1987b : 210) taklidin gelişimdeki önemini "belirli bir bilişsel yapının diğerine göre ne kadar geliştiğini öğrenmek istiyorsak bunu taklit yoluyla test edebiliriz" biçiminde ifade etmektedir. $\mathrm{Bu}$ özellik genel olarak çocuğun kültürel gelişiminin en önemli adımlarından biridir. Kurama göre taklit, belirli bir etkinliğin bilinçsiz ve basit bir tekrarı değildir. Aksine taklit (yapısalcıların ve toplumsal öğrenmecilerin görüşlerinden farklı olarak), çözüm aşamasındaki bir probleme ilişkin yapısal ilişkilerin, etkinlik öncesinde çocuk tarafından anlaşılmış ya da fark edilmiş olmasını gerektirmektedir. Buna göre çocuk, her şeyi taklit edemez, "taklit, ancak 
taklit edilen şeyle ilgili bir anlayış kazanıldığında söz konusu olur" (Vygotsky, 1987a : 96), yani çocuk ancak kendi bilişsel potansiyel alanı içindeki şeyleri taklit edebilir. Böylelikle "taklit, çocuğun bağımsız bir biçimde yapamadığı ancak öğretilebilen ya da yönlendirme, işbirliği ya da yol açıcı sorularla yapabildiği her şeyi" kapsamaktadır (Vygotsky, 1987a : 202).

\section{Gelişimin Kaynağı Olarak Toplumsal Etkileşimler}

Vygotsky'nin kuramında birey ve toplum arasındaki karş̧lıklı bağlılı̆̆ın doğasını anlatan en önemli özellik, bireysel gelişimin kaynă̆ının, toplumsal etkileşimlerde olduğuna ilişkin açıklamasıdır (Palincsar, 1998; John-Steiner ve Mahn, 1996). Vygotsky bu durumu "gelişimin toplumsal durumu" biçiminde açıklamaktadır. Buna göre çocuğun her bir gelişim evresinde kazandığı psikolojik işlevler, çocuğun bulunduğu yaş döneminde çevresiyle girdiği özel nitelikli etkileşimlerde söz konusu olan aracı eylemlerin sonucudur (Karpov, 2003). Yetişkinler ve daha yetenekli akranlar, çocukla çevresi arasında aracı bir yere sahiptirler ve etkileşimin koşullarını değiştirirler. Aracılar (yetişkin ya da akran), çocuk için, nesneleri seçer, değiştirir, kapsamını genişletir ve yorumlar (Kozulin ve Presseisen, 1995). Çocuğun gelişimine aracılık eden bu toplumsal durum, her gelişim evresinde değişmekle birlikte çocuk bu toplumsal durumun her zaman bir parçasıdır. Çünkü bu durum, temelde çocuğun kendi deneyim ve eylemleri yoluyla oluşur (Mahn, 2003). Ancak çocuğun deneyimleri, içinde bulunduğu çevre tarafından belirlendiği için çevrenin her zaman kontrol edici bir anlamı vardır. Çevrenin kontrol edici işlevi, çocuğun her bir gelişim dönemindeki psikolojik işlevlerinin ne olacağını değil nasıl kazanılacağını belirleyen en önemli koşuldur. Ancak bu koşul, çocuktan çevreye ya da çevreden çocuğa yönelik olan etkileşimler yoluyla gerçekleşmektedir (Tudge ve Scrimsher, 2002).

Etkileşim sırasında, çocukla yetişkin ya da akranlar arasında tanımlanmış, toplumsal içeriği olan bir işbirliği söz konusu olmaktadır. İşbirliği, çocuğun anlamlı şey ve bu anlamlı şeye nasıl ulaşabileceğine karar vermesinde yardımcı olan kültürel aracı işaret ve araçları içermektedir (Tomasello, 1999). Bir anlamda başta aile ve sonra toplumun diğer üyeleri, çocuk için Super ve Harkness'ın (2002) da tanımladığı "gelişimsel yuva"yı (developmental niche) yaratmaktadır. Bu kavram, bireyin çevresindeki kültürel temelli bağlamsal özelliklerin yakınlığını gösteren bir yapıyı tanımlamaktadır. Bu yapı çocuğun kültürel çevresini, birbirinden ayrı fakat birbirini tamamlayan üç alt kültürel sisteme bölmektedir: günlük yaşam alanlarını (toplumsal ve fiziksel) düzenleyen bir yapı olarak kültür; geleneksel uygulamaları içeren bir yapı olarak kültür; bakıcının inanç ve kültürel gelenekleriyle oluşmuş psikolojik bir gerçeklik olarak kültür (Ando, 2003).

Vygotsky, çocuğun, gelişimin toplumsal durumu içerisinde aktif bir bileşen olarak yer aldığını belirtmesine rağmen bunun ne düzeyde olduğunu ayrıntılı olarak değerlendirmemektedir. Ona göre çocuk, dış dünyayı temel alan eylemleri yoluyla gelişmektedir. Ancak çocuk bağımsız bir biçimde eylemde bulunmaktan çok, 
yetişkin ya da akranlarla birlikte ortak eylemlerde bulunmaktadır. Bu ortak eylemler, her bir gelişim evresinde farklılık göstermektedir. Yani 3 yaşındaki bir çocukla 6 yaşındaki bir çocuğun toplumsal etkileşim biçimi farklılık göstermektedir. $\mathrm{Bu}$ farklılık, her bir gelişim evresinde kazanılan ve bir sonraki evre için temel sağlayan özelliklerdeki farklıklardan kaynaklanmaktadır. Bununla birlikte Zaporozhets (1997) her bir yaş döneminin, çocuğun bulunduğu döneme özgü ve içinde bulunduğu kültürün özelliklerini içeren "yol açıcı eylem"leri ile tanımlandığını belirtmektedir. Bir eylemin belirli bir yaş döneminde "yol açıcı" olarak tanımlanmasının nedeni, bu eyleme yönelik gerçekleşen aracı işlevlerin çocuk için önemli gelişimsel başarılara yol açmasıdır. Ancak yol açıcı eylemin oluşması, çocukla yetişkin ya da akran arasındaki işbirliğini gerektirmektedir. Bu görüsse göre çocuk, bu işbirliği yoluyla yeni yol açıcı eylemlere yönelmesini sağlayacak bilişsel süreç ve beceriler kazanması yanında daha sonraki eylemlere güdülenmesini sağlayacak kazançlar da elde etmektedir (Korpov, 1995; Korpov, 2003).

Vygotsky kuramında, belirli bir problem durumunda çocukla yetişkin arasındaki işbirliğinin, farklı biçimlerde gelişebileceğini belirtmiştir. Ona göre herhangi bir problem durumunda yetişkin;

- $\quad$ çocuğa bu tür bir problemi nasıl çözmesi gerektiğini gösterip onun problemi gösterdiği biçimde çözüp çözemediğine bakabilir,

- $\quad$ problemi kendisi çözmeye başlayıp çocuktan bitirmesini isteyebilir,

- $\quad$ çocuğun gelişim düzeyinin üstündeki bir problemi yetenekli bir başka kişi (örneğin kardeşi ya da başka bir yetişkin) ile işbirliği yaparak çözeceğini varsayabilir,

- $\quad$ çocuğa problem çözümüne yönelik ilkeleri verir, yol açıcı sorular sorar ve onun için problemi analiz ederek problemi çözmesini sağlayabilir (Chaiklin, 2003).

Bununla birlikte kuramda, çocukla yetişkin arasındaki öğretmeye dayalı etkileşimi açıklayan kavramsal tanımlar verilmemektedir. Çocukla ona aracılık eden yetişkin ya da akran arasındaki etkileşimler, etkileşimin niteliğine bağlı olarak farklı biçimlerde kavramsallaştırılmaktadır. Rogoff (1995) bu tür etkileşimleri açıklarken çocuğun bulunduğu tüm toplumsal çevreleri (aile, kardeşler, akranlar, okul, öğretmenler, komşular) ve kültürü içeren bir kavram olarak "rehberliğe dayalı katılım"1 (guided participation) önermektedir. Wood (1998) ise, etkileşimlerde yetişkin desteğini ya da müdahalesini vurgulayan bir kavram olarak "iskele kurma" (scaffolding) kavramını önermektedir.

\section{Rehberliğe Dayalı Katılım}

Rehberliğe dayalı katılım kavramı, sosyokültürel tarih kuramına yönelik analizlerin kişilerarası boyutu ile ilgilidir. Burada çocukların ve onların toplumsal eşlerinin (yetişkinler, akranlar) sosyokültürel olarak yapılandırılmış bir eylemi ya da görevi (küçük çocukların bakımı, ev işlerinin yapılması gibi), karşılıklılığı da içeren bir katılım süreci içinde yerine getirmeleri üzerinde durulmaktadır. Ancak kavram, hangi tür etkileşimlerin rehberliğe dayalı katılım olduğunun belirlenmesini 
sağlayacak işlevsel bir tanım sunmaktan çok eylemlere katılımı içeren kişilerarası sorumluluk ve düzenlemeleri vurgulamaktadır.

Kavramdaki "rehberlik" ifadesi, toplumsal ve kültürel değerler ile toplumun yetkin bireyleri tarafindan sunulan yönlendirmeleri içermektedir (Rogoff, 1995). Rehberlik, sadece açık, belirgin öğretim durumlarını değil aynı zamanda önceki kuşaklar tarafindan oluşturulan ve eylem modellerine dayanan özel yönlendirmeleri de vurgulamaktadır. Katılım ise, bir eyleme yönelik olarak, hem gözlem sürecini hem de karşılıklı katılımı içermektedir. Gözlem ve karşılıklılık ile çocuğun ve onun toplumsal eşinin (bazen bir yetişkin bazen bir başka çocuk) eylemi birlikte planlamaları, düzenlemeleri ve her ikisinin de kendi yetenekleri oranında eyleme katkıda bulunmaları kastedilmektedir. Ancak sözü edilen katılımın, simetrik olması ya da ortak eylemi içermesi zorunlu değildir. Buna göre örneğin, diğerlerini gözleyen ve onların aldığı kararları izleyen bir çocuğun başkaları tarafindan verilmiş kararlara doğrudan bir katkısının olması gerekmez. Bunun yerine bir çocuk, belli bir problem üzerinde çalışırken diğerleri tarafindan belirlenmiş kurallar çerçevesinde ancak onların rehberliğinde ve onlarla etkileşim içerisinde eylemde bulunmaktadır. Ayrıca katılım, ikili etkileşim türleri ile sınırlı olmayıp o topluma özgü gizli gelişim hedefleri düzeyinde tanımlanması gereken tüm ilişsi sistemlerini de (şu anda olan ya da olmayan partnerler, gruplar ya da kurumlar) içermektedir (Rogoff, Göncü ve Mosier 1993). Böylelikle rehberliğe dayalı katılımla temsil edilen kişilerarası analiz düzlemi, bireylerin diğer insanlarla ve araçlarla katıldıkları günlük yaşam olaylarını ve kendi kendilerine ve diğerleri ile birlikte yaptıkları düzenlemeleri içerir. $\mathrm{Bu}$ süreç, basit bir etkileşimin ötesinde çocuğun yetişkinle birlikte, kültürel aracılar yoluyla gelişimine iliş̧kin bir anlayış sunmaktadır.

$\mathrm{Bu}$ doğrultuda rehberliğe dayalı katılım, çocuğun ve toplumun geliştiği tüm durumların ayrılmaz parçası olarak, bireysel, kişilerarası ve kültürel süreçler üzerinde durmaktadır (Rogoff, 1995). Bireysel düzlemde çocuğun, bulunduğu toplumun bir üyesi olarak kendi eylemleri, kişilerarası düzlemde başkaları ile olan ilişkileri ve kültürel düzlemde ise bu ilişkileri biçimlendiren kültürel süreçler vurgulanmaktadır. Bu süreç içerisindeki etkileşimler, örtülü ya da açık, yüzyüze ya da uzak, benzer özelliklerin paylaşıldı̆̆ yakın insanlarla ya da tanıdık olmayan uzak insanlarla (akranlar, komşular gibi) paylaşılan amaçları içerebilmektedir. Burada vurgulanan daha çok çocuğun kültürel süreçlere katılımıdır. Bununla birlikte katılımın niteliği çocuğun yaşına bağlı olarak değişmektedir (Vandermaas-Peller, Way ve Umpleby, 2002). Buna göre, çocuğun yaşına bağll olarak belirli görev durumları ile ilgili deneyimi arttıkça buna bağlı olarak hem katılımın hem de yetişkin rehberliğinin niteliği değişmektedir. Kavramın karşıllıklılığı içeren doğası içinde değerlendirildiğinde, çocuğa rehberlik eden kişinin tesadüfi öğretme durumlarını kullanması, çocuğun her bir öğrenme durumunda zamana bağlı olarak gösterdiği değişime, en önemlisi de başarıya bağlıdır. Buna göre, çocuk bir görev durumunda başarılı oldukça, yetişkin desteğinin biçimi de değişmekte, karmaşıklaşmakta ve dolayısıyla çocuğun katılımı da farklılaşmaktadır. 
Böylelikle rehberliğe dayalı katılımın genel özellikleri aşağıdaki biçimde özetlenebilmektedir:

1- Yetkin kişi / kişiler ya da akranlar, çocuğun varolan bilgi ve becerileri ile yeni görevin gereklilikleri arasında bir köprü kurarlar. Çocuklar yardım olmaksızın, yeni görevin gerekliliklerini, kendi bilgi ve becerileri ile birleştiremezler ve başarısız olurlar. Oysa çocuklar bu görevi yardımla yerine getirebilirler.

2- Çocuğun eylemde bulunduğu bağlamda sağlanan öğretimler ve yardımlar yoluyla, çocuğa problem çözümüne yönelik bir yapı sağlanmış olur. Örneğin, tek başına bloklarla bir iskele kurmaya başlayan bir çocuk bir süre sonra bu amaçtan uzaklaşabilir. Oysa bir yetişkin yardımı ya da desteği ile çocuğa aralıklı olarak bu amacı hatılatılabilir ve amaca uygun eylemleri desteklenebilir.

3- Yetişkin ya da öğretici konumundaki kişi problem çözmeye yönelik eylemin dışında görünüyorsa da gerçekte aktif olarak o da eylemin içerisindedir ve problemin başarılı bir biçimde çözülebilmesinde rol oynar.

4- Etkili rehberlik, görevle ilgili sorumluluğun, yetkin kişiden çocuğa transferini içermektedir (Wood, 1998).

Bununla birlikte rehberliğe dayalı katılımı içeren tüm etkileşimler, öğrenme ve öğretime dayalı değildir (Rogoff 1990, Rogoff, Göncü ve Mosier 1993). Çocuğun yetişkinle yaptığı günlük ve alışıldık bir etkinlik (evin düzenlenmesi, yemek hazırlama gibi) içerisinde ya da akranlarla oynanan bir oyun sırasında da söz konusu olabilmektedir. Burada asıl önemli olan etkileşimin, karşıllklılığı ve katılımı içeren biçimlerinin varlığıdır.

\section{İskele Kurma}

İskele kurma (scaffolding) kavramı, çocukların öğrenmesini ve gelişimini desteklemede yetişkin ya da daha yetkin akranların rolünü tanımlayıcı ve açıklayıcı bir metafor olarak kullanılmaktadır. Ancak metaforik doğası nedeniyle, öğretim sürecinin nasıl olması gerektiği ile ilgili tam olarak açık ve kesin ipuçları vermemektedir (Stone, 1998). Bununla birlikte yetişkin ile çocuk arasındaki etkileşime ilişkin bir anlayış sunmaktadır.

$\mathrm{Bu}$ kavram da tıpkı diğeri gibi Vygotsky tarafindan tanımlanmış ya da açılanmış bir kavram değildir. Ancak Vygotsky'nin yakınsak gelişim alanı fikrine dayanmaktadır. Mercer ve Fisher (1993), yakınsak gelişim alanı ile iskele kurma arasındaki ilişkiyi açıklarken, yakınsak gelişim alanının potansiyel gelişim özelliklerinin ortaya çıkmasını sağlayan "sorumluluğu paylaşma" yönünün, iskele kurma kavramının en önemli özelliği olduğunu belirtmektedir. Burada vurgulanmak istenen, öğrenme ve gelişimde toplumsal etkileşimler ve bu etkileşimlerin karşılıklılığı içeren doğasıdır. Toplumsal etkileşimler yoluyla çocuk, varolan gelişim düzeyine uygun aracılı araçları kullanarak başkalarıyla iletişim kurma denemeleri 
yapmaktadır. Bu etkileşimler, çocuğun bireysel düzlemde aracılı araçların kullanımı ile ilgili repertuarını geliştirmesi yanında toplumsal düzlemde onun bu etkileşimlerde nasıl daha etkin bir rol alabileceğine ilişkin ipuçları da sağlamaktadır. $\mathrm{Bu}$ gelişimsel durum ve sahip olunan ipuçları çocuğu, varolan gelişim özelliklerinin ötesindeki potansiyel gelişim düzeyine taşımaktadır (Verenikina, 2003). Böylelikle toplumsal etkileşimler ve karşıllklılık, çocuğun potansiyel gelişim düzeyine ulaşmasını sağlayan temel itici ilkeler olarak işlev görmektedir ve bu durum "iskele kurma" kavramının da temelini oluşturmaktadır. Çünkü iskele kurma metaforu, temelde çocuğun varolan gelişim düzeyi ile çözemediği problem durumları ile karşılaşması sırasında yaşadığı bilişsel zorlanmanın, yetkin bir başka kişi tarafından kontrollü bir biçimde sunulması fikrine dayanmaktadır.

Wood, Bruner ve Ross (1976), iskele kurmayı, başlangıçta öğrenen kişinin kapasitesinin üzerinde olan bir görevle bağlantılı tüm özelliklerin bir başka kişi (öğretici, yetenekli bir yetişkin ya da akran) tarafindan kontrol edilmesi ve böylelikle, onun sadece bu özelliklere dikkatinin çekilerek kendi yetenek sınırları içerisinde görevi tamamlaması biçiminde açıklamaktadır. Görevin temel özelliklerinin vurgulanmasının amacı, çocuğun hem görevle bağlantılı amaçlara dikkatinin çekilmesi hem de bu dikkatin görev boyunca sürmesinin önemli olmasıdır. Böylelikle çocuk, görev üzerinde tam bir kontrol elde ettiğinde onu tamamlamak konusunda daha fazla sorumluluk alacak ve sonuçta karşsll1klıl1k sağlanacaktır (Roehler ve Cantlon, 1997). Kontrol sağlama ve sorumluluk alma biçiminde kavramsallaştırılan iskele kurma sürecinde yetişkinin en önemli rolü, öğrenme çevresini düzenleme, kullanılan teknik ya da sembolik araçları tanıtma, görevin ortaya konmasını ve onun varolan bağlam içine yerleştirilmesini sağlama biçiminde özetlenmektedir (Coltman, Petyaeva, Anghilera, 2002). Bundan sonraki düzey ise, öğrenme süreci boyunca çocuğu destekleyici bir etkileşimi sağlamayı içermektedir.

Stone (1998), yetişkin ya da yetkin akranın bu süreçteki en önemli bileşenler olarak kabul edilmesinin yanlış olacağını belirtmektedir. Yetişkin desteğinin niteliği, çocuk ve yetişkin arasındaki ilişki, ifade edilen anlamlar, problem durumuna yüklenen değer, görevin kendisi ve onunla bağlantılı olarak gösterilen davranışlar da önemlidir. Örneğin, gelişmiş toplumlarda çocuklar için özel öğrenme ortamları yaratılırken geleneksel toplumlarda çocuğun gözlem ve bireysel katılımı yoluyla öğrenmesi desteklenmektedir.

Berk ve Winsler (1995), etkili bir iskele kurma sürecinin bazı önemli bileşenleri olduğunu belirtmektedirler. Bunlardan ilki, çocuğun ilginç ve kültürel olarak anlamlı ve işbirliğine dayalı bir problem çözme durumuna aktif olarak katılmasıdır (birlikte problem çözme). Katılımcılar yetişkin-çocuk ya da çocukçocuk biçiminde olabilir ve burada önemli olan nokta, iki kişinin aynı amaç için birlikte çalışmasıdır. Bu Vygotsky'nin (1978) bilişin toplumsal eylem sırasında uyarıldığı ile ilgili görüşlerini destekleyen bir bileşendir. Buna göre, çocuklar 
açısından en iyi öğrenme yaşantıları, bir problemin çözümünü başkası / başkaları ile etkileşim içinde oldukları durumlarda gerçekleşmektedir.

İkinci bileşen karşllıklılıktır. Karş1lıklılık, problem durumu içerisinde yer alan iki kişinin göreve farklı amaçlarla başlamalarına karşın sonra ortak bir anlayışa ulaşmaları anlamına gelmektedir (Wells, 1999). Gerçek bir işbirliğinin ve etkili bir iletişimin oluşabilmesi için, her iki tarafin da aynı amacı paylaşması gerekmektedir. $\mathrm{Bu}$ durum, yetkin olan yetişkin ya da akranın çocuğa uygun bir destek verebilmesi için gerekli bir koşuldur. Karşılıklılık, temelde iletişimde bakışaçısı alma fikrine dayanmaktadır (Rogoff, 1990). Buna göre uygun bir iskele kurma sürecinde yetişkin, çocuğun varolan gelişimsel düzeyine göre görevleri, kullanılacak materyalleri, amaçları ve bu amaca nasıl ulaşılabileceği ile ilgili yolları belirlemelidir. Bu süreçte yetişkin, problemin çocuk için kolay ya da zor gelen yönlerini süreç içinde yeniden düzenleyerek karşılıklık kuralına uyduğunu göstermektedir.

İskele kurmanın etkileşimde duygusal tarzı vurgulayan üçüncü bileşeni, yakınlık ve sorumluluk göstermedir. Çocuğun bir görevle ilgili aktif katılımı, karşısındaki kişinin ona gösterdiği yakınlık ve sıcaklık ile ilgili olduğu kadar uygun durumlarda verilen sözel ve sözel olmayan ödüllerle de yakından ilişkilidir. Katılım bir süreç olarak değerlendirildiğinde, bu bileşen, çocuğu problemin çözümüne güdülemek ve bu güdülenmeyi sürecin ilerleyen aşamalarında da devam ettirebilmek açısından önemlidir (Berk ve Winsler, 1995). Güdülenmenin gerçekleşmesi büyük oranda çocuğun görevin zorluğu ile ilgili algısına bağlıdır. Bir problem, çocuğun varolan yetenekleri ile çözemeyeceği kadar zor ya da kolay olduğunda bu güdülenmeyi olumsuz yönde etkilemektedir. İskele kurmanın dördüncü bileşeni de iskele kurmanın bu yöndeki içeriğini oluşturmaktadır.

İskele kurma sürecinin en önemli bileşeni, süreç boyunca çocuğu yakınsak gelişim alanı içerisinde tutmaktır. Bunu gerçekleştirmek için yetişkinin öncelikle, hem görevi hem çevreyi çocuğun varolan gelişim düzeyine (gerçek gelişim düzeyi) göre düzenlemesi ya da yapılandırması gerekmektedir (Wells, 1999). Bu süreç, sözel olmayan yollarla olabileceği gibi açıkça da olabilir. Buna göre yetişkin etkileşimde görevle bağlantılı ipuçlarını belirleyerek ya da seçerek çocuğa verir. Ayrıca görevin yerine getirilmesi ile ilgili kurallar da görev öncesinde yetişkin tarafindan belirlenebilir. Böylelikle çocuğun gerçek gelişim özelliklerine uygun bir görev durumu ve çevre yaratılmış olur. Örneğin görev çocuk için çok kolay olduğunda yetişkin, amacı değiştirerek, göreve yeni bileşenler ekleyerek ya da çıkararak görevin zorluk derecesini arttırabilir. Yetişkinin çocuğu yakınsak gelişim alanı içerisinde tutmasının bir diğer yolu da, görevin yerine getirilmesi sırasında çocuğun varolan ihtiyaçları ve yeteneği ile bağlantılı olarak aracılık miktarını düzenlemektir (Berk ve Winsler, 1995). Aracılık miktarı, çocuğa görevle ilgili sunulan yardım veya öğretim miktarını göstermektedir. Yetişkin görev sırasında çocuğun performansına göre sağladığı yardım ya da destekle onun belli bir zorluk düzeyinde kalmasını sağlamaktadır. Bu zorluk düzeyi çocuğun potansiyel gelişim özelliklerini kullanması 
açısından önemlidir. Ancak yetişkinin sağlayacağı yardım ya da desteğin türü duruma, göreve ya da çocuğa ve yetişkine bağlı olarak değişebilmektedir (Coltman, Petyaeva ve Anghileri, 2002).

İskele kurmanın diğerlerinden farklı olarak niteliksel özelliklerini vurgulayan son bileşeni, çocuğu kendi eylemlerini kendi kendine düzenleyebilecek (selfregulation) duruma getirmektir (Berk ve Winsler, 1995). Bu durum yetişkinin, çocuk verilen problem durumu ile ilgili olarak bağımsız ve doğru bir biçimde eylemde bulunduğu anda desteğini ve yardımını kesmesini gerektirmektedir. Ayrıca çocuğun problemle ilgili sorun ya da zorluklarla uğraşmasına izin vermek ve ancak gerçekten yardıma ihtiyaç duyduğunda ona destek olmak bu bileşenin bir diğer boyutunu oluşturmaktadır. Çocuğun problemi çözmeye yönelik çabalarına izin vermek ve gerektiğinde ona destek olmak, çocuğu bir "yürütücü” olarak görevin içinde tutmak açısından da önemlidir. Çünkü diğer bileşenlerle birlikte düşünüldüğünde, iskele kurma sürecinde, çocuğun aktif olması ve kendisinin de süreç üzerinde kontrolünün olması öğrenme açısından önemli bir gerekliliktir (Verenikina, 2003). Bundan dolayı, yetişkinin görev süresince çocuğun çözümü bulmasına yardımcı olacak sorular sorma ya da çözüm önerileri sunma çabaları öğrenmeyi ve kendi kendine düzenleme sürecini arttıracaktır (Roberts ve Barnes, 1992). Özetle iskele kurma, yetişkin ya da yetkin akranın bir problem ya da görev durumunda çocukla birlikte, karşıllklılığın olduğu yakın bir etkileşim içinde problemi çözmeleri ya da görevi tamamlamaları anlamına gelmektedir. Bu işbirliği sırasında yetişkin, uygun destek ya da yardımı sağlayarak, sözel ya da sözel olmayan ipuçları ile düşünmeyi sağlayarak ve çocuğun varolan becerileri oranında görevle ilgili sorumluluklar almasına izin vererek çocuğun kendi kendini düzenleme becerisini kazanmasına yardım etmektedir.

\section{SONUÇ}

Vygotsky'nin kültürel-tarihsel gelişim kuramı genel olarak, bilişsel ve dil gelişiminde toplumsal bağlamın etkilerinden bahsetmektedir. Kuramda gelişimin; toplum, dil ve toplumsal etkileşimler yoluyla biçimlendirildiği belirtilmektedir. Toplumun kendisi, etkileşimlerin içerik ve düzeyini belirleyen kültürel aracı araçları içermektedir. Bu araçlar, başta dil olmak üzere belirli bir kültürü paylaşan insanların etkileşimlerini yönlendiren her türlü bilgi sistemini içermektedir. Kurama göre bu araçlar, çocuğun anlamlı diğerleri ile kurduğu etkileşimler yoluyla kazanılmaktadır. Toplumsal etkileşimler bu bağlamda özellikle önemli bir yere sahiptir. Yetişkin rehberliği ya da yetkin akranlarla kurulan etkileşimler, çocuğun sadece aracilı araçları ya da stratejileri öğrenmesine değil bu bilgileri içselleştirmesine yani toplumsal olanın kişi içi bir özellik kazanmasına da yardımcı olmaktadır. Vygotsky etkileşimlerin, yakınsak gelişim alanı olarak tanımlanan özel bir bölge içinde gerçekleştiğini belirtmektedir. Bu bölge çocuğun varolan gelişim özellikleri ile potansiyel gelişim özellikleri arasındaki uzaklığı tanımlamaktadır. Kuramda yetişkin ya da yetkin akranlarla kurulan etkileşimler ve özellikle bu etkileşimlerde çocuğa sunulan yardım ve destek ile sağlanan işbirliğinin, çocuğun gelişimi açısından önemli olduğu belirtilmektedir. 


\section{KAYNAKLAR}

Ando, C. (2003). Interview analysis in technology access and use: Developmental niche and guided participation. Mevcut internet adresi: http://ldt.stanford.edu/ chicando/folio/papers/chika_rogoff.doc

Berk, L.E., Winsler, A. (1995). Scaffolding children's learning: Vygotsky and Early childhood education. Cilt 7, Washington DC: National Association for the Education of Young Children.

Brown, A.L., Ferrara, R.A. (1989). Diagnosing zones of proximal development. J.Wertsch (Düz.). Culture, Communication and Cognition: Vygotskian perspectives içinde, New York: Cambridge University Press.

Chaiklin, S. (2003). The zone of proximal development in Vygotsky's analysis of learning and instruction. A.Kozulin, B.Gindis, V.S.Ageyev, S.M.Miller (Düz.). Vygotsky's Educational Theory in Cultural Context içinde, New York: Cambridge University Press.

Cole, M. (1989). The zone of proximal development: where culture and cognition create each other. J.Wertsch (Düz.) Culture communication and cognition: Vygotskian perspectives içinde, New York: Cambridge University Press.

Cole, M. (1995). Socio-cultural-historical psychology: some general remarks and a proposal for a new kind of cultural-genetic method. J.V.Wertsch, P.Del Rio, A.Alvarez (Düz.) Sociocultural Studies içinde, New York: Cambridge University Press.

Coltman, P., Petyaeva, D., Anghilera, J. (2002). Scaffolding learning through meaningful tasks and adult interaction. Early Years, sayı 22, no 1, syf. 39-49.

Davydov, V.V., Radzikhovski, L.A. (1989). Vygotsky's theory and the activityoriented approach in psychology. J.Wertsch (Düz.) Culture communication and cognition: Vygotskian perspectives içinde, New York: Cambridge University Press.

Fass, P. (2003). Children and globalization. Journal of Social History, cilt 36, say1 4, syf. 963-977.

Fernyhough, C. (1996). The dialogic mind: A dialogic approach to the higher mental functions. New Ideas in Psychology, sayı 14, no 1, syf. 47-62.

John-Steiner, V., Mahn, H. (1996). Sociocultural approaches to learning and development: A Vygotskian framework, Educational Psychologist, sayı 31, no 3-4, syf. 191-206.

Karpov, Y.V. (1995). L.S. Vygotsky as the founder of a new approach to instruction. School Psychology International, say1 16, syf. 131-142. 
Karpov, Y.V. (2003). Development through the lifespan. İçinde A.Kozulin, B.Gindis, V.S.Ageyev, S.M.Miller (Düz.) Vygotsky's educational theory in cultural context, NY: Cambridge Pres.

Kozulin, A., Presseisen, B.Z. (1995). Mediated learning experience and psychological tools: Vygotsky's and Feuerstein's perspectives in a study of student learning. Educational Psychologist, sayı 30, no 2, syf. 67-75.

Kozulin, A. (1999). Sociocultural contexts of cognitive theory. Human Development, sayl 42 , syf. 78-82.

Lee, B. (1989). Intellectual origins of Vygotsky's semiotic analysis. İçinde J.Wertsch (Düz.) Culture communication and cognition: Vygotskian perspectives, New York: Cambridge University Press.

Mahn, H. (2003). Periods in Child Development. İçinde A.Kozulin, B.Gindis, V.S.Ageyev, S.M.Miller (Düz.) Vygotsky's Educational Theory in Cultural Context, NY: Cambridge Pres.

Mercer, N., Fisher, E. (1993). How do teachers help children to learn? An analysis of teachers' interventions in computer-based activities. Learning and Instruction, say1 2, syf. 339-355.

Palincsar, A. S. (1998). Social constructivist perspectives on teaching and learning. Online Annual Review Psychology [0066-4308/98/0201-0345\$08.00], 49. Mevcut İnternet Adresi: www.ulakbim.gov.tr

Piaget, j., Inhelder, B.,(1969), The Psychology of Child, NY: Basic Books.

Ratner, C. (1998). Prologue to Vygotsky's collected works Volume 5. İçinde R.Rieber, A.Carton (Düz.) The collected works of L.S.Vygotsky (Cilt 5). New York: Plenum Press.

Roberts, R.N., Barnes, M.L. (1992). "Let momma show how": Maternal-child interactions and their effects on children's cognitive performance. Journal of Applied Developmental Psychology, sayı 13, syf. 363-376.

Roehler, L.R., Cantlon, D.J. (1997). Scaffolding: A powerful tool in social constructivist classrooms. İçinde K.Hogan ve M. Pressley (Düz.), Scaffolding Student Learning. Cambridge: Brookline Books.

Rogoff, B., Mistry, J., Göncü, A., Mosier, C. (1993). Guided participation in cultural activity by Toddlers and Caregivers. Monographs of the Society for Research in Child Development, say1 58, no 8, syf. 5.

Rogoff, B. (1990). Apprenticeship in thinking. NY: Oxford University Press.

Rogoff, B. (1995). Observing sociocultural activity on three planes: participatory appropriation, guided participation, and apprenticeship. İçinde J.V. Wertsch, P. Del Rio, A. Alvarez (Düz.), Sociocultural studies of mind. NY: Cambridge University Press. 
Scribner, S. (1989). Vygotsky’s uses of history. İçinde J.Wertsch (Düz.) Culture communication and cognition: Vygotskian perspectives, New York: Cambridge University Press.

Smagorinsky, P. (1995). The social construction of data: Methodological problems of investigating learning in the zone of proximal development. Review of Educational Research, say1 65, syf 191-212.Van Der Veer, R. (1986). Vygotsky's Developmental Psychology. Psychological Reports, 59, 527-536.

Stone, A. (1998). The metaphor of scaffolding: Its utility for the field of learning disabilities. Journal of Learning Disabilities, sayı 3, numara 4, syf. 344-364.

Super, C.M., Harkness, S. (2002). Culture structures the environment for development. Human Development, say1 45, syf. 270-274.

Tomasello, M. (1999). The cultural origins of human cognition. Cambridge, MA: Harvard University Press.

Tudge, J.; Scrimsher, S. (2002). Lev S. Vygotsky. İçinde B. J. Zimmerman ve D. H. Schunk (Düz.), Educational psychology: A century of contributions. Mahwah, NJ: Lawrence Erlbaum Associates.

Van der Veer. R. (1986). Vygotsky's Developmental Psychology, Psychological Reports, 59, 527-536.

Vandermaas-Peller, M., Way, E., Umpleby, J. (2002). Guided participation in a cooking activity over time. Early Child Development and Care, sayı 172, syf. 547-554.

Verenikina, I. (2003). Understanding scaffolding and zpd in educational research, Australian Association of Educational Research Conference, Auckland, New Zealand.

Mevcut internet adresi: www.aare.edu.au/03pap/ver03682.pdf

Vygotsky, L.S. (1978). Mind in Society. (Düz. M. Cole, V.Joh-Steiner, S. Scribner, E. Souberman). Massachusetts: Harvard University Press.

Vygotsky, L.S. (1985). Düşünce ve Dil. Çeviren: Semih Koray, İstanbul: Kaynak Yayınları.

Vygotsky, L.S. (1987a). The development of scientific concepts in childhood. İçinde R.Rieber, A.Carton (Düz.) The collected works of L.S.Vygotsky (Cilt 1). New York: Plenum Press.

Vygotsky, L.S. (1987a). The genetic roots of thinking and speech. İçinde R.Rieber, A.Carton (Düz.) The collected works of L.S.Vygotsky (Cilt 1). New York: Plenum Press.

Vygotsky, L.S. ve Luria, A. (1994a). Tool and symbol in child development. İçinde R.Van der Veer ve J.Valsiner (Düz), The Vygotsky Reader. Oxford: Basil Blackwell Ltd. 
Vygotsky, L.S. (1994b). The problem of the cultural development of the child. İçinde R.Van der Veer ve J.Valsiner (Düz), The Vygotsky Reader. Oxford: Basil Blackwell Ltd.

Vygotsky, L.S. (1994c). The problem of the environment. İçinde R.Van der Veer ve J.Valsiner (Düz), The Vygotsky Reader. Oxford: Basil Blackwell Ltd.

Wertsch, J. (1997). Vygotsky and the social formation of mind, Cambridge: Harward University Press.

Wells, G. (1999). The zone of proximal development and its implications for learning and teaching. İçinde G.Wells (Düz.) Dialogic inquiry: Towards a sociocultural practice and theory of education. Cambridge: Cambridge University Press. Mevcut internet adresi: http://www.oise.utoronto.ca/ gwells/resources/ZPD.html

Wells, G. (2006). Semiotic mediation, dialogue and the construction of knowledge. Mevcut internet adresi: http://education.ucsc.edu/faculty/gwells/Files/Papers_Folder/Semiotic\%20Medi ation\%20and\%20Education.htm

Wertsch, J., del Rio,P., Alverez, A. (1995). Sociocultural studies: history, action, and mediation. J.V. Wertsch, P. Del Rio, A. Alvarez (Düz.), Sociocultural studies of mind içinde. Cambridge: Cambridge University Press.

Wertsch, J. (1997). Vygotsky and the social formation of mind, Cambridge: Harward University Press.

Wood, D., Bruner, J., Ross, G. (1976). The role of tutoring in problem solving, Journal of Child Psychology and Psychiatry, sayı 17, syf. 89-100.

Wood, D. (1998). How children think and learn (2.Baskı), Oxford: Blackwell Publishers.

Zaporozhets, A.V. (1997). Principal problems in the ontogeny of the mind. Journal of Russian and East European Psychology, sayı 35, no 1, syf. 53-94. 